\title{
Editorial
}

\section{Towards comprehensive global monitoring of food environments and policies to reduce diet-related non-communicable diseases}

In July we featured the food environment in our journal, and it emerges as our hot topic in the last issue of the year as well.

Food environments have been defined ${ }^{(1-3)}$ and studied ${ }^{(4-8)}$ in many different ways, but most broadly they include a combination of physical, economic, policy and sociocultural surroundings, opportunities and conditions that influence an individual's food choices. In general, food environments are considered to be unhealthy rather than healthy, as energy-dense, nutrient-poor processed food products, usually containing high levels of salt, sugar and fat, are increasingly more available, less expensive and more heavily promoted than healthy foods ${ }^{(9)}$. Thus, current food environments seem to play a major role in shaping unhealthy diets and driving energy overconsumption $^{(10)}$. This issue of Public Health Nutrition highlights several articles that deal with food environments, broadly defined.

\section{Physical and economic access}

Current evidence is suggestive of an association between retail food environments and dietary outcomes; however, substantial heterogeneity in study designs, methods and measurement tools makes it difficult to draw firm conclusions $^{(6,11)}$. Studies in the current issue reflect this heterogeneity. In a study conducted in Melbourne, Australia, for example, women who lived further from the nearest supermarket were less likely to consume low amounts of fast food ${ }^{(12)}$, but living in a food desert in Detroit, USA, was not significantly associated with residents' $\mathrm{BMI}^{(13)}$. Food cost is another important aspect of the food environment, and in this issue Holm et al. ${ }^{(14)}$ found a moderate reduction in the incidence of cardiovascular diseases and some cancers in Denmark when the rate of value-added tax on fruit and vegetables was halved and the tax on fats was increased.

\section{Food labelling}

Food labelling is an aspect of the food environment that may affect food purchase decisions. In this issue, Beeken and Wardle ${ }^{(15)}$ found that policy support for labelling of foods was relatively high among UK adults, while
Auchincloss et $a l^{(16)}$ qualitatively explored how responsiveness of US consumers to menu labelling might be improved. Food labels are futile if they are inaccurate, however, and other studies in this issue suggest the need for monitoring and regulation. A survey of foods sold in a supermarket in Brazil indicated that nutrition facts labels or no trans-fat claims on food product packages were unreliable ${ }^{(17)}$. In Australia $31 \%$ of non-alcoholic beverages, breakfast cereals and cereal bars carrying health claims did not meet the nutrient profiling criteria of the proposed Australian health claim regulation ${ }^{(18)}$.

\section{Children's food environments}

To the extent that childhood behaviours can have measurable and lasting effects on health, food environments of children and policies affecting these are worth close examination. Ensaff et $a l^{(19)}$ and Nicklas et $a l^{(20)}$, for example, demonstrate that improving school food standards is critical, as current food choices are predominantly unhealthy and portion sizes excessive. Indeed, school food policies might be among the best food environmentrelated policies to target for change. In a study in Washington State, USA, researchers, policy experts and other stakeholders ranked policies regarding nutrition standards in schools and child-care facilities as having higher political and implementation feasibility and impact compared with other food policies ${ }^{(21)}$. Apart from the foods served at schools, however, food environments for children outside schools can be quite unfavourable as well and less easily amenable to change. Studies by Manganello et al. ${ }^{(22)}$, Pettigrew et $a l^{(23,24)}$ and Mchiza et $a l^{(25)}$ in this issue show that food advertising through parenting magazines, sports sponsorships, Internet and television were predominantly for foods of poor nutritional quality. Moreover, according to Lythgoe et $a l^{(26)}$, a significant number of products marketed towards children in UK supermarkets were higher in fat, sugar and salt than their non-children's equivalents marketed to the general population.

\section{No monitoring, no action}

The food environment is increasingly recognized as a primary influence on dietary behaviour and on people's 
abilities to maintain their health and well-being. Its importance is recognized among the general public as well. In a study in the $\mathrm{UK}^{(15)}$, the majority of adults sampled attributed obesity to the food environment. In the $\mathrm{USA}^{(27)}$, caregivers of African-American children rated lower pricing of less healthy foods, limited access to healthier food retailers and targeted advertisements as particularly influential of children's food choices and consumption.

Yet no country to date has implemented a systematic and comprehensive approach to survey its food environments, and 'no monitoring' translates into 'no action'. The main obstacle to improving food environments to date has been the slow and insufficient development and implementation of strong government policies, largely hindered by food industry practices ${ }^{(9,28)}$. In Europe, for example, the Confederation of Food and Drink Industries successfully lobbied against the introduction of a front-of-pack traffic light labelling system ${ }^{(29)}$. In Latin America, healthy food laws introduced by several nations lag in implementation due to powerful lobbying by the food and advertising industries ${ }^{(30)}$. Such instances led Moodie et al. in their recent paper $^{(28)}$ to refer to these industries as 'corporate disease vectors', and Dr Margaret Chan, in her opening speech at the 2013 Health Promotion Conference in Helsinki, to declare 'Big Food, Big Soda, and Big Alcohol' as among the biggest challenges facing health promotion ${ }^{(31)}$.

In May 2013 a global political commitment was made towards a comprehensive plan for the prevention and control of non-communicable diseases (NCDs) and for a monitoring framework to measure progress on twenty-five indicators towards nine targets ${ }^{(32)}$. However, this newly adopted framework is deficient in monitoring key aspects of food environments and policies impacting on those.

\section{Development of a monitoring framework for food environments and policies}

The International Network for Food and Obesity/NCDs Research, Monitoring and Action Support (INFORMAS) was recently founded to fill this important gap ${ }^{(33)}$. INFORMAS offers standardized stepwise approaches to monitor several key aspects of food environments transformable by government and private-sector policies and actions. These include food composition ${ }^{(34)}$, food labelling ${ }^{(35)}$, exposure of children to unhealthy food promotion ${ }^{(36)}$, food provision in different settings ${ }^{(37)}$, food availability in communities ${ }^{(11)}$, prices and affordability of healthy $v$. less healthy diets ${ }^{(38)}$, and the impacts of trade and investment agreements on food environments ${ }^{(39)}$.

In addition to monitoring key aspects of food environments, INFORMAS has proposed a Government Healthy Food Environment Policy Index (Food-EPI) to assess government policies and actions towards good practice ${ }^{(40)}$. A separate assessment of private-sector actions and practices $^{(41)}$ draws on experience from the recently launched Access to Nutrition Index (ATNI) ${ }^{(42)}$, supplemented with the measurement of less visible practices, such as lobbying, political donations and corporate philanthropy. INFORMAS also aims to monitor the diet quality of populations ${ }^{(43)}$, with the dietary share of ultraprocessed foods as one of the indicators, similar to the approach used by Moubarac et al. ${ }^{(44)}$ in this issue.

This new monitoring initiative aims to increase effectiveness in influencing policy makers and private-sector organizations to shift their efforts towards creating healthy food environments. Monitoring should also provide a clear focus on where policy actions are most needed.

\section{Implementation of the monitoring framework}

Pilot tests for the INFORMAS monitoring modules are currently underway in countries of varying size and income. For some modules, or parts of them, monitoring is already being performed, as shown in this issue by King et $a l^{(45)}$, who present the approach for independent monitoring of food advertising on television in Australia. All countries globally are invited to implement the INFORMAS monitoring framework ${ }^{(33)}$, fully or in part, and to collect representative data on the healthiness of their food environments and the policies, actions and practices of government and private-sector organizations as they relate to food environments.

The global INFORMAS database ${ }^{(33)}$ will provide international best practice exemplars or benchmarks against which to compare progress of countries, and possibly companies, on improving food environments. It will also allow for evaluation of the impact of new national policies and changes in food environments on diets and NCDs, which is rarely possible through randomized controlled trials. In the long run, INFORMAS aims to be a costeffective and policy responsive contribution towards decreasing the global diet-related NCD burden. Efforts such as INFORMAS are a critical next step if we accept our role in informing and catalysing policy responses, and in holding governments and private-sector organizations accountable for their policies and actions.

Stefanie Vandevijvere Associate Editor Email: Stefanie.Vandevijvere@wiv-isp.be

Marilyn Tseng

Editor-in-Chief

Email: mtseng@calpoly.edu

\section{References}

1. Story M, Kaphingst KM, Robinson-O'Brien R et al. (2008) Creating healthy food and eating environments: policy and environmental approaches. Annu Rev Public Health 29, 253-272. 
2. Glanz K, Sallis JF, Saelens BE et al. (2005) Healthy nutrition environments: concepts and measures. Am J Health Promot 19, 330-333, ii.

3. Swinburn B, Egger G \& Raza F (1999) Dissecting obesogenic environments: the development and application of a framework for identifying and prioritizing environmental interventions for obesity. Prev Med 29. 563-570.

4. Lytle LA (2009) Measuring the food environment: state of the science. Am J Prev Med 36, 4 Suppl., S134-S144.

5. Charreire H, Casey R, Salze P et al. (2010) Measuring the food environment using geographical information systems: a methodological review. Public Health Nutr 13, $1773-1785$.

6. Caspi CE, Sorensen G, Subramanian SV et al. (2012) The local food environment and diet: a systematic review. Health Place 18, 1172-1187.

7. Gustafson A, Hankins S \& Jilcott S (2012) Measures of the consumer food store environment: a systematic review of the evidence 2000-2011. J Community Health 37, 897-911.

8. McKinnon RA, Reedy J, Morrissette MA et al. (2009) Measures of the food environment: a compilation of the literature, 1990-2007. Am J Prev Med 36, 4 Suppl., S124-S133.

9. Swinburn BA, Sacks G, Hall KD et al. (2011) The global obesity pandemic: shaped by global drivers and local environments. Lancet 378, 804-814.

10. Swinburn B, Sacks G \& Ravussin E (2009) Increased food energy supply is more than sufficient to explain the US epidemic of obesity. Am J Clin Nutr 90, 1453-1456.

11. Ni Mhurchu $\mathrm{C}$, Vandevijvere $\mathrm{S}$, Waterlander WE et al. (2013) Monitoring the availability of healthy and unhealthy foods and non-alcoholic beverages in community and consumer retail food environments globally. Obes Rev $\mathbf{1 4}$ Suppl. 1, 108-119.

12. Thornton LE, Jeffery RW \& Crawford DA (2013) Barriers to avoiding fast-food consumption in an environment supportive of unhealthy eating. Public Health Nutr 16, 2105-2113. http:// corporateeurope.org/news/red-light-consumer-information

13. Budzynska K, West P, Savoy-Moore RT et al. (2013) A food desert in Detroit: associations with food shopping and eating behaviours, dietary intakes and obesity. Public Health Nutr 16, 2114-2123.

14. Holm AL, Laursen MB, Koch M et al. (2013) The health benefits of selective taxation as an economic instrument in relation to IHD and nutrition-related cancers. Public Health Nutr 16, 2124-2131.

15. Beeken RJ \& Wardle J (2013) Public beliefs about the causes of obesity and attitudes towards policy initiatives in Great Britain. Public Health Nutr 16, 2132-2137.

16. Auchincloss AH, Young C, Davis AL et al. (2013) Barriers and facilitators of consumer use of nutrition labels at sitdown restaurant chains. Public Health Nutr 16, 2138-2145.

17. Silveira BM, Gonzalez-Chica DA \& da Costa Proença RP (2013) Reporting of trans-fat on labels of Brazilian food products. Public Health Nutr 16, 2146-2153.

18. Hughes C, Wellard L, Lin J et al. (2013) Regulating health claims on food labels using nutrient profiling: what will the proposed standard mean in the Australian supermarket? Public Health Nutr 16, 2154-2161.

19. Ensaff H, Russell J \& Barker ME (2013) Meeting school food standards - students' food choice and free school meals. Public Health Nutr 16, 2162-2168.

20. Nicklas TA, Liu Y, Stuff JE et al. (2013) Characterizing lunch meals served and consumed by pre-school children in Head Start. Public Health Nutr 16, 2169-2177.

21. Johnson DB, Quinn EL, Podrabsky M et al. (2013) Perceived impact and feasibility of strategies to improve access to healthy foods in Washington State, USA. Public Health Nutr 16, 2178-2187.
22. Manganello JA, Clegg Smith $\mathrm{K}$, Sudakow $\mathrm{K}$ et al. (2013) A content analysis of food advertisements appearing in parenting magazines. Public Health Nutr 16, 2188-2196.

23. Pettigrew S, Rosenberg M, Ferguson R et al. (2013) Game on: do children absorb sports sponsorship messages? Public Health Nutr 16, 2197-2204.

24. Pettigrew S, Tarabashkina L, Roberts M et al. (2013) The effects of television and Internet food advertising on parents and children. Public Health Nutr 16, 2205-2212.

25. Mchiza ZJ, Temple NJ, Steyn NP et al. (2013) Content analysis of television food advertisements aimed at adults and children in South Africa. Public Health Nutr 16, 2213-2220.

26. Lythgoe A, Roberts C, Madden AM et al. (2013) Marketing foods to children: a comparison of nutrient content between children's and non-children's products. Public Health Nutr 16, 2221-2230.

27. Baskin ML, Herbey I, Williams R et al. (2013) Caregiver perceptions of the food marketing environment of AfricanAmerican 3-11-year-olds: a qualitative study. Public Health Nutr 16, 2231-2239.

28. Moodie R, Stuckler D, Monteiro C et al. (2013) Profits and pandemics: prevention of harmful effects of tobacco, alcohol, and ultra-processed food and drink industries. Lancet 381, 670-679.

29. Corporate Europe Observatory (2010) A red light for consumer information: the food industry's €1-billion campaign to block health warnings on food. http:// corporateeurope.org/news/red-light-consumer-information (accessed September 2013)

30. Fraser B (2013) Latin American countries crack down on junk food. Lancet 382, 385-386.

31. Chan M (2013) WHO Director-General addresses health promotion conference. Opening address at the 8th Global Conference on Health Promotion, Helsinki, Finland, 10 June 2013. http://www.who.int/dg/speeches/2013/ health_promotion_20130610/en/index.html (accessed June 2013).

32. World Health Organization (2013) Draft action plan for the prevention and control of non-communicable diseases 2013-2020. Sixty-sixth World Health Assembly Provisional Agenda item 13.2. Report by the Secretariat. Geneva: WHO.

33. Swinburn B, Sacks G, Vandevijvere S et al. (2013) INFORMAS (International Network for Food and Obesity/ non-communicable diseases Research, Monitoring and Action Support): overview and key principles. Obes Rev 14, Suppl. 1, 1-12.

34. Neal B, Dunford EK, Sacks G et al. (2013) Monitoring the levels of important nutrients in the food supply. Obes Rev 14, Suppl. 1, 49-58.

35. Rayner M, Wood AT, Barquera S et al. (2013) Monitoring the health-related labelling of foods and non-alcoholic beverages in retail settings. Obes Rev 14, Suppl. 1, 70-81.

36. Kelly B, King L, Baur L et al. (2013) Monitoring food and non-alcoholic beverage promotions to children. Obes Rev 14, Suppl. 1, 59-69.

37. L'Abbe M, Schermel A, Minaker L et al. (2013) Monitoring foods and beverages provided and sold in public sector settings. Obes Rev 14, Suppl. 1, 96-107.

38. Lee A, Ni Mhurchu C, Hawkes C et al. (2013) Monitoring the price and affordability of foods and diets globally. Obes Rev 14, Suppl. 1, 82-95.

39. Friel S, Hattersley L, Barquera S et al. (2013) Monitoring the impacts of trade agreements on food environments. Obes Rev 14, Suppl. 1, 120-134.

40. Swinburn B, Vandevijvere S, Kraak VI et al. (2013) Monitoring and benchmarking government policies and actions to improve the healthiness of food environments: a 
proposed Government Healthy Food Environment Policy Index. Obes Rev 14, Suppl. 1, 24-37.

41. Sacks G, Swinburn B, Kraak VI et al. (2013) A proposed approach to monitor private-sector policies and practices related to food environments, obesity and non-communicable disease prevention. Obes Rev 14, Suppl. 1, 38-48.

42. GAIN - Global Alliance for Improved Nutrition (2012) Access to Nutrition Index. http://www.accesstonutrition.org/ (accessed September 2013).
43. Vandevijvere S, Monteiro C, Krebs-Smith SM et al. (2013) Monitoring and benchmarking population diet quality globally: a step-wise approach. Obes Rev 14, Suppl. 1, 135-149.

44. Moubarac JC, Martins AP, Claro RM et al. (2013) Consumption of ultra-processed foods and likely impact on human health. Evidence from Canada. Public Health Nutr 16, 2240-2248.

45. King L, Hebden L, Grunseit A et al. (2013) Building the case for independent monitoring of food advertising on Australian television. Public Health Nutr 16, 2249-2254. 